\section{Shooting of giant reed (Arundo donax L.) stem cuttings in cold greenhouse}

\author{
Piergiorgio Gherbin, ${ }^{1}$ Simone Milan, ${ }^{2}$ \\ Giuseppe Mercurio, ${ }^{1}$ Antonio Scopa ${ }^{1}$
}

1School of Agricultural, Forest, Food and Environmental Sciences, ${ }^{2}$ Department of Science, University of Basilicata, Potenza, Italy

\begin{abstract}
The increasing interest in Arundo donax, a perennial lignocellulosic species only reproducing by propagation, requires the setup of cheap, simple and reliable techniques. Considering these targets, stem cutting offers considerable advantages. The present investigation aimed to compare: i) plants obtained by different propagation methods (by rhizome and micropropagation mother plants); ii) plants obtained by stem cuttings from basal, central and apical parts of the stem; iii) different planting periods (spring, summer, autumn). The obtained results showed that the number of new shoots from stem buds was: i) higher in the spring and lower in the summer planting period; ii) higher from cuttings obtained by micropropagated than rhizome mother plants, both in spring and summer plantings; iii) decreasing passing from the basal to the apical stem portion; iv) partly unexpressed in the autumn planting period; v) lower from one-year stem cuttings as compared to two-year stem cuttings.
\end{abstract}

\section{Introduction}

Arundo donax L., also known as giant reed, bamboo reed, river cane, canne de Provence, is a non-food, geophyte, herbaceous and rhizomatous perennial plant, with a $\mathrm{C}_{3}$ photosynthetic pattern, belonging to the Poaceae family. It is widely diffused in Mediterranean, subtropical and warm temperate regions. ${ }^{1,2}$ A relevant part of the dedicated scientific literature exclusively considers this species as a major weed, probably due to its high adaptability to marginal lands. ${ }^{3}$

The high production potential, at least comparable with other $\mathrm{C}_{4}$ species, ${ }^{4,5}$ makes $A$. donax one of the most yielding and promising crops, its biomass being indicated as a great source of energy in Mediterranean, USA and Australian environments. ${ }^{6-8}$ This kind of feedstock may be suitable to processed at different technological levels. ${ }^{9}$ First, through direct com- bustion, but also in biological conversion processes such as the production of second generation bioethanol ${ }^{10-12}$ with a general great attitude to energy generation. ${ }^{13}$

Furthermore, the increasing demand of cellulose pulp for paper production and the progressive shortage of conventional raw materials for pulping (such as wood and its derivatives) determine a renewed interest towards herbaceous plant species and crop residues, especially in countries with insufficient forest resources. Among perennial herbaceous crops, A. donax revealed high potential in relation to biomass production, as well as for the good quality of cellulose pulp, suitable for paper industry and useable for many types of industrial products. ${ }^{14-16}$

Giant reed rarely produces gametophytes and consequent vital seeds, ${ }^{17}$ especially when introduced outside its area of origin, ${ }^{18,19}$ confined in the East/Middle-East areas. ${ }^{20}$ Therefore, in natural environments asexual propagation occurs, almost exclusively via rhizomes or sprouting from stem buds. Giant reed grown in the Italian environment has been recently identified having polyphyletic origin. ${ }^{21}$ Many authors have examined its production as a crop, comparing different cultivation techniques. ${ }^{5,8,22-26}$ The vegetative propagation of $A$. donax via stem cuttings has a limited scientific bibliography, while the use of rhizome as propagation material is the most common technique, widely applied in various cultivation experiences even if a labour-intensive and time-consuming process. ${ }^{27,28}$ The lack of sexual reproduction is a negative characteristic when considering $A$. donax as an energy crop, since both propagation and genetic improvement became difficult to be carried out. ${ }^{29}$

From an agronomical point of the view, stem cutting multiplication shows disadvantages mainly related to the limited number of plantlets obtained per each plant portion; this negative aspect could be overcome applying in vitro propagation methods. Nowadays, developed protocols are available on these regards. ${ }^{30-32}$ In the past ${ }^{22}$ and recently, ${ }^{33-38}$ open field propagation methods using stem cuttings has been reconsidered and studied. This technique seems to be technically and economically reasonable ${ }^{39}$ however, a better understanding regarding the influence of the type of propagating organ and its characteristics (e.g. position, size, age) on the shooting and rooting capacity is needed. Timing and rooting circumstances are also relevant aspects to be deeply investigated.

Stem cuttings implants appear to be cost effective, since the main mechanization issues has been resolved. ${ }^{40}$ This implant method might solve the principal barriers related to rhizomes planting, primarily due to the high cost of this propagation material.

This study, under controlled conditions in a
Correspondence: Piergiorgio Gherbin, School of Agricultural, Forest, Food and Environmental Sciences (SAFE), University of Basilicata, Viale dell'Ateneo 10, 85100 Potenza, Italy.

Tel.: +39.971.205236.

E-mail: piergiorgio.gherbin@unibas.it

Key words: Arundo donax L.; Stem cutting; Agamic propagation; Shoot emergence.

Contributions: PG designed the experiment and wrote the initial draft; SM contributed to wrote the initial draft; GM carried out the experiment; AS reviewed the paper.

Conflict of interest: the authors declare no potential conflict of interest.

Received for publication: 3 November 2015. Accepted for publication: 29 November 2015.

This work is licensed under a Creative Commons Attribution-NonCommercial 4.0 International License (CC BY-NC 4.0).

(0) Copyright P. Gherbin et al., 2016

Licensee PAGEPress srl, Italy

International Journal of Plant Biology 2016; 7:6294 doi:10.4081/pb.2016.6294

cold greenhouse, deepens response to propagation by cuttings, comparing the effects of different portions and mother plant of different origin.

\section{Materials and Methods}

The research was carried out in Southern Italy $\left(40^{\circ} 38^{\prime} \mathrm{N}, 15^{\circ} 48^{\prime} \mathrm{E}, 850 \mathrm{~m}\right.$ a.s.l.) in cold greenhouse, in the course of 2011. A. donax stems were taken from stock plants of the third vegetative season, obtained through both micropropagation and rhizome cuttings. Stems were collected in three different periods: spring (March 9), summer (June 7) and autumn (September 15) from field cultivation.

Regarding the autumn period, clamps singled out stems produced in the previous vegetative season (2010) from the current one. Thus, autumn stem cuttings were separately collected with respect to their different age and defined as old and new stem cuttings, respectively. ${ }^{22,41}$ Starting ten centimeters from the soil surface, the above-ground part of giant reed was collected, sectioned into three onemeter portions, thus forming the following groups: i) basal (from 10 to 110 above the soil surface); ii) central (from 110 to 210 above the soil surface); iii) apical (from 210 to 310 above the soil surface).

Each group was composed by twenty cut- 
tings and the number of total buds per single portion was counted.

Stem cuttings were planted horizontally, ten centimeters depth in the soil. In order to avoid soil cracking, a substrate mixture composed by equal amounts of silty-clay soil, river sand and common nursery substrate was used. Afterwards, soil moisture content was kept close to field capacity through sprinkled water supplies, during the whole observation period. Substrate temperature was measured through a geothermometer equipped with a ten centimeters depth probe (Figure 1).

Emerged shoots have been counted, on average, five times per week; these observations were stopped when no other new emergences were detected within a week. At the end of each survey period, all stem cuttings were explanted in order to evaluate possible changes on underground buds (buds sprouted but no shoot emerged). The obtained datasets have been expressed as percentage of emerged shoots relative to the total stem cutting buds. The best fitting curve function was applied to graphically show the time trend of shoots appearance. The obtained curves have been studied directly comparing their confidence intervals $(\mathrm{P} \leq 0.05)$ according to the approach originally proposed by Monteleone and colleagues. ${ }^{42}$

\section{Results}

\section{Spring planting}

Substrate temperature generally increased (Figure 1A) during this considered period (69 days, from March 11 to May 20). A higher increase was observed in T-max compared to T-min. Average values increate from 16 and $7^{\circ} \mathrm{C}$, during the first decade, respectively.

Sharp thermal declines were recorded in the second and fourth decade, with minimum temperatures below $10^{\circ} \mathrm{C}$.
Concerning the shoots obtained from stem cuttings derived by micropropagated plants, basal portions showed higher shoot emergence rates, compared to the other two treatments; starting to differ from 29 and 43 days after planting (DAP) for the apical and central portion, respectively, and reaching a final rate of $50 \%$ from 50 DAP (Figure 2A). Central and apical stem portions have 12 days to reach the maximum shoot emergence rates. Their final value was 19 and 51\% lower compared to the basal portion, respectively.

Regarding shoots from stem cuttings derived by rhizome propagated plants (Figure 2B), the trend was similar to stem cuttings obtained by micropropagated plants. Lower shooting rates have been registered from the apical portions compared to the others. Starting from 43 DAP the central portions differed from the apical, while from 53 DAP from the basal, leading to a final average value of $29 \%$. On the other hand, basal and central stem cutting portions, even if denoting differences in favor of the central portions around 47 DAP, showed no statistically different maximum values ( $42 \%$ on average).

A shoot emergence starting from 25 DAP was observed for stem cuttings derived by micropropagation, a week in advance than those derived by rhizome; such a difference of earliness was confirmed until they reached the maximum rate value. Furthermore, apical portions always showed earliness together with a lower final rate of emergence, when compared to the other portions; these latter presented differences among them only in the case of stem cuttings derived from micropropagation.

Lastly, it is worth noting the best performance highlighted by basal portions of micropropagated cuttings.

\section{Summer planting}

Substrate temperature generally increased (Figure 1B) during this considered period (42 days, from June 8 to July 21), from 26 and $19^{\circ} \mathrm{C}$ in the first decade to 22 and $32^{\circ} \mathrm{C}$ in the last decade, for T-max and T-min respectively. Considering the central part of the considered period, the substrate average temperatures were high $\left(\mathrm{T}-\max 30^{\circ} \mathrm{C}\right)$ and rather constant. The shoot emergence rate of micropropagated stem cuttings (Figure 3A), showed a significant differentiation between 20 and 23 DAP, with the best final recorded performance (21\%) for the basal sections and the worst (9\%) for the apical portions. Stem cuttings from rhizome mother plants (Figure 3B) have shown lower shooting rates from buds of the central portions, compared to the other portions, starting from 18 DAP. This has led to a maximum final rate of 9 against $13 \%$ recorded for the remaining portions. The shoots emergence started around 15 DAP regardless of the mother plants origin; reaching final maximum rates with a limited difference among treatments, around 33 DAP. Summer period similarly to the spring, showed the basal portion of stem cuttings derived by micropropagation with the highest emergence rate.

\section{Autumn planting}

Substrate temperature generally decreased (Figure 1C) during this considered period (59 days, from September 16 to November 14). Tmax decreased from 22 to $20^{\circ} \mathrm{C}$, while the decreasing pattern of T-min was more marked, from 15 to $10^{\circ} \mathrm{C}$, respectively in the first and in
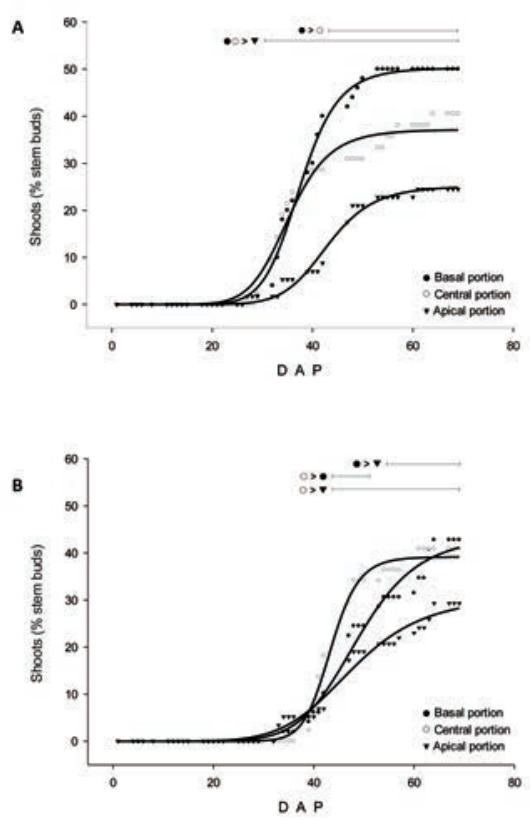

Figure 2. Shoot emergence from different stem portions of plants propagated by micropropagation (A) and by rhizomes (B) in spring period (segments in the upper graph part indicate the differentiation period between curves).
Figure 1. Maximum and minimum substrate temperatures recorded in spring (A), summer $(B)$ and autumn $(C)$ observation periods.

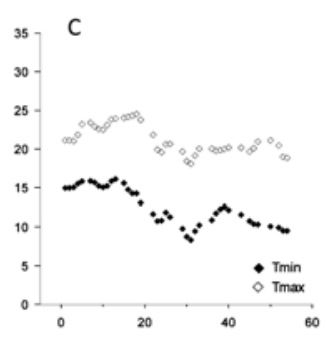

Days after planting (DAP) 
the last decade. A thermal loss in the end of third decade was recorded, with minimum temperatures of $7^{\circ} \mathrm{C}$. In this period, no relevant differences on shoot emergence rates has been observed among the considered propagation mother plants. Shoot emergence rates from stem cuttings produced in the previous year (old cuttings, Figure 4) started between 20 and 25 DAP and lasted for 4 weeks. No significant differences were observed among the various stem portions. An average of $30 \%$ of emerged shoots was recorded. At the explant time a $29 \%$ of the total stem buds produced normally formed shoots, but without a sufficient dimensional growth to emerge.

Shoots derived from new cuttings (Figure 5) have shown different responses with respect of old cuttings, in particular: i) a lower shooting rate of apical portions, compared to the other stem portions (8vs. 20\%); ii) a slower emergence progression, leading to lower final rates; iii) the absence of small-sized, not emerged shoots at the explant time.

\section{Discussion}

The experimental data collected regarding the correlation between mother-plant propagation methods and propagation capacities showed, on average, no relevant differences between rhizome and micropropagated mother-plant types. However, cuttings obtained by micropropagated mother-plant stem sections showed, generally, more encouraging results. Moreover, springtime seems to be the most suitable period for the propagation of $A$. donax by means of stem cuttings. It has been possible to observe significant differences on the extent of shoots emergence, among the different planting periods and the different examined stem portions. In particular, a $38 \%$ of shoot emergence rate has been observed for spring planting, three times higher than summer planting and nearly doubled compared with autumnal period (Figure 6). Such differences are not attributable to different water availabilities, although the thermal factor has primarily influenced the stem buds susceptibility to produce shoots. ${ }^{38}$

In terms of number of emerged shoots, in the autumnal period an intermediate value between the other periods, spring and summer, was recorded. However, during this observation period, not yet emerged shoots detected at the explant time (therefore not accounted for), has expressed a propagative potential close to the one achieved in spring plantation time.

As observed in earlier experiences, ${ }^{37,38,43}$ the production of new shoots from stem buds has a relevant decrease trend in acropetal direction (Figure 7), with a $37 \%$ difference between basal and apical portions.

The different attitude to produce shoots from stem buds is a key factor to be taken into account during both the mechanical harvest of stem portions for field propagation and the planning of field implantation. Stem cutting production and the following open field planting, starting directly from mother plants, may be considered a relatively simple mechanical operation. Given recent achievements and efforts in these regards, ${ }^{40}$ particular attention should be given not to include stem cuttings with shoots presence, from open field mother plants. These type of shoot develops in late
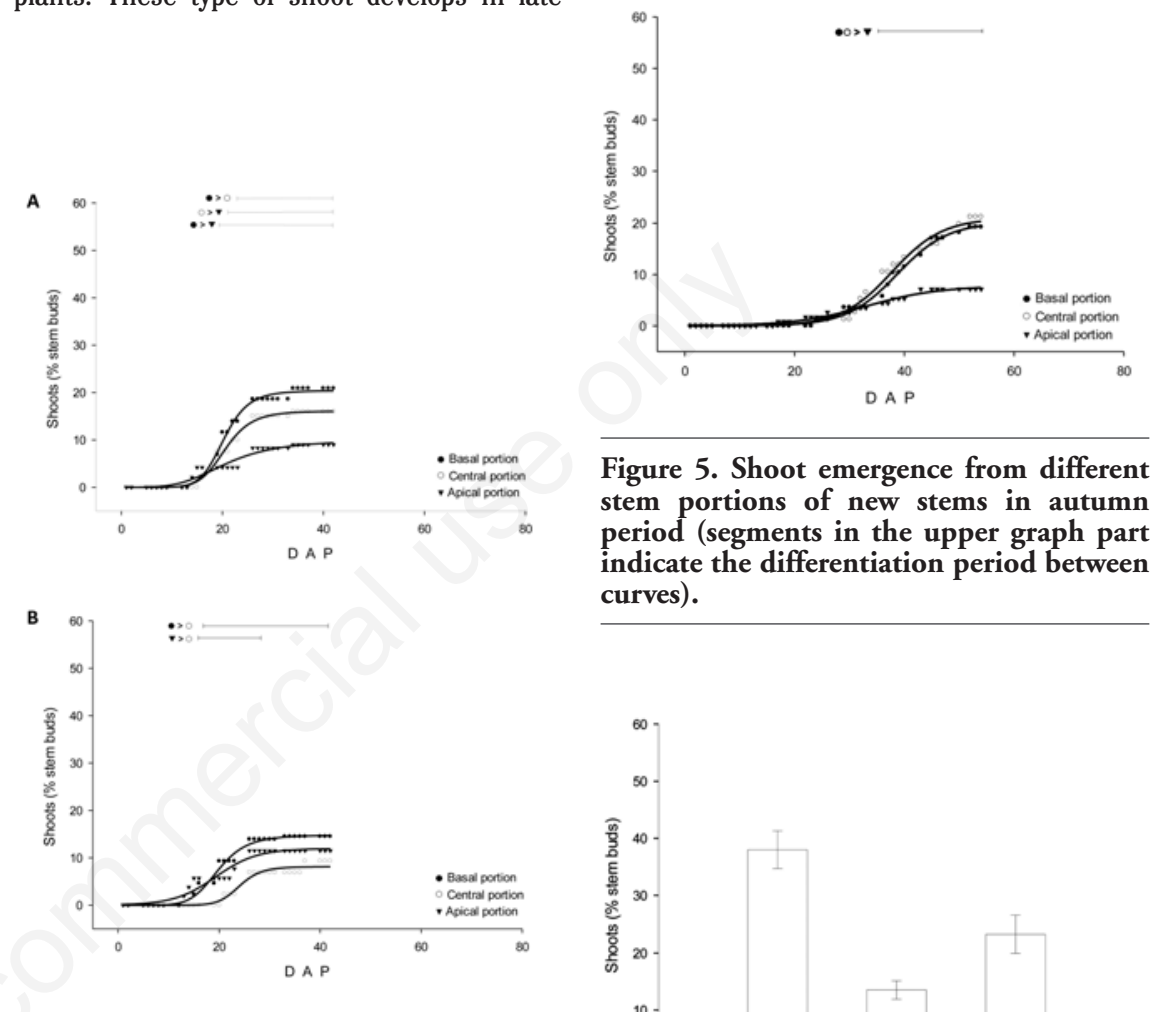

Figure 3. Shoot emergence from different stem portions of plants propagated by micropropagation $(\hat{A})$ and by rhizomes $(\mathbf{B})$ in summer period (segments in the upper graph part indicate the differentiation period between curves).

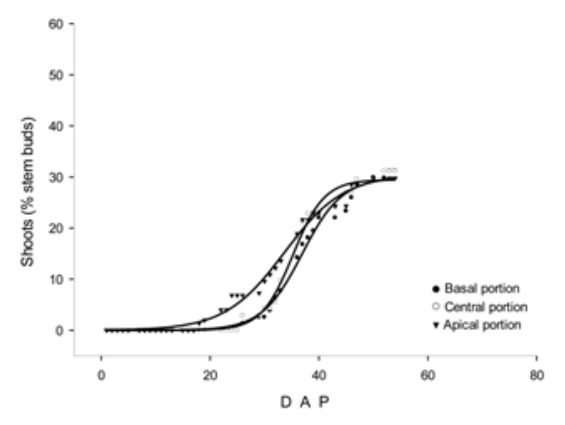

Figure 4. Shoot emergence from different stem portions of old stems in autumn period.
Figure 5. Shoot emergence from different stem portions of new stems in autumn period (segments in the upper graph part indicate the differentiation period between curves).

summer on two years old stems, generally in the apical part for approximately 1/3-1/4 of the stem height. ${ }^{22,44}$ In order to use such propagative material in case of open field plantation, a topping method has to be established simultaneously with stem cutting collection, as such shoots would be interfering with mechanical planting operations. Further studies on the basal and central portion cuttings planted in autumn period might be of help to better understand the nature of such an unexpressed

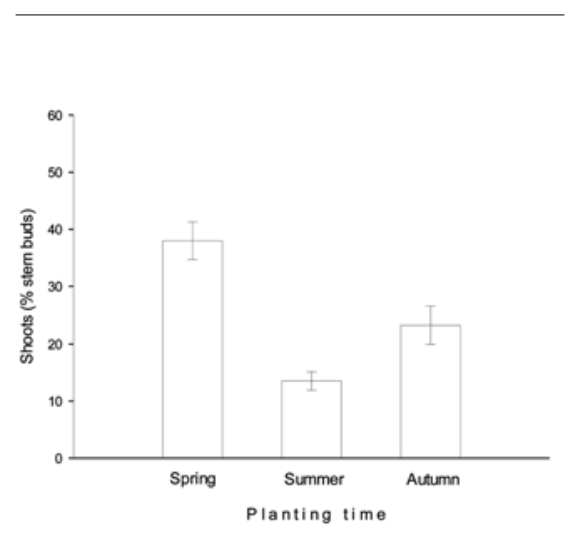

Figure 6. Shoot emergence average at the end of each observation period (vertical bar $=$ standard error).

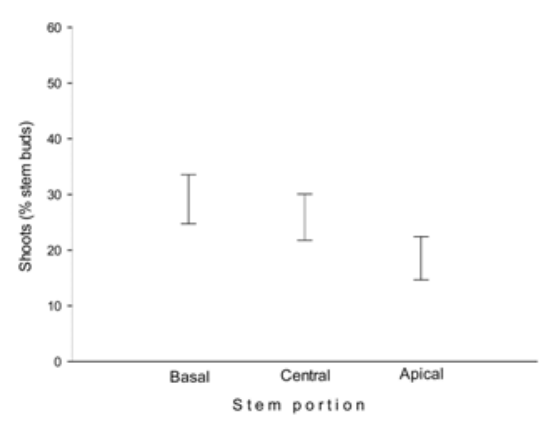

Figure 7. Shoot emergence average of compared stem portions at the end of observations (vertical bar = standard error). 
bud potential, possibly due to thermal conditions. It will be appropriate to investigate autumn stem cuttings plantation in open field conditions, to evaluate both the autumnal and springtime shoots emergence rates. It would be possible then, to evaluate: i) cold resistance/tolerance on both emerged shoots and underground buds, in winter time; ii) irrigation incidence during the initial planting period at that time of the year, absolutely needed in the case of spring and summertime cultivations. ${ }^{45,46}$

\section{Conclusions}

The obtained results underlined a greater new shoots emergence rate from stem buds planted in springtime, the best performance was obtained from basal stem portions and stem cuttings by micropropagated mother plants. Less satisfactory emergence rates has been shown from summertime planting, apical stems portions and stems produced during the same planting year (new cuttings). It remains to be deepened the knowledge about the autumn planting time of two years old stem cuttings. Indeed, a good predisposition in formation of new shoots is expected together with the possibility to limit irrigations in early planting stages when open field cultivations are considered.

\section{References}

1. Zohary M. Plant life of Palestine: Israel and Jordan. Science 1962;136:523.

2. Mariani C, Cabrini R, Danin A, et al. Origin, diffusion and reproduction of the giant reed (Arundo donax L.): a promising weedy energy crop. Ann Appl Biol 2010;157:191-202.

3. Fan P, Marston A. How can phytochemists benefit from invasive plants? Nat Prod Commun 2009;4:1407-16.

4. Rossa B, Tüffers AV, Naidoo G, Willert DJ. Arundo donax L. (Poaceae) a $\mathrm{C}_{3}$ species with unusually high photosynthetic capacity. Bot Acta 1998;111:216-21.

5. Christou M, Mardikis M, Alexopoulou E. Research on the effect of irrigation and nitrogen upon growth and yields of Arundo donax L. in Greece. Aspects of Applied Biology 2001;65:47-55.

6. Lewandowski I, Scurlock JM, Lindvall E, Christou M. The development and current status of perennial rhizomatous grasses as energy crops in the US and Europe. Biomass Bioenerg 2003;25:335-61.

7. Angelini LG, Ceccarini L, Nassi o Di Nasso N, Bonari E. Comparison of Arundo donax and Miscanthus $\mathrm{x}$ giganteus in a longterm field experiment in central Italy: analysis of productive characteristics and energy balance. Biomass Bioenerg 2009;33:635-43.

8. Williams CMJ, Biswas TK, Black ID, et al. Use of poor quality water to produce high biomass yields of giant reed (Arundo donax L.) on marginal lands for biofuel or pulp/paper. Acta Hortic 2008;806:595-602.

9. Fagnano M, Impagliazzo A, Mori M, Fiorentino N. Produzione dell'Arundo donax in ambiente collinare meridionale. Proceedings of the XXXIX SIA Congress, 2010 Sept 20-22, Rome, Italy. pp 207-8.

10. Ask M, Olofsson K, Di Felice T, et al. Challenges in enzymatic hydrolysis and fermentation of pretreated Arundo donax revealed by a comparison between SHF and SSF. Process Biochem 2012;47:1452-9.

11. Scordia D, Cosentino SL, Copani V, Testa G. Produzione di bioetanolo di seconda generazione dalla canna comune (Arundo donax L.). Ital J Agron 2013;8:25-33.

12. Cotana F, Cavalaglio G, Nicolini A, et al. Lignin as co-product of second generation bioethanol production from ligno-cellulosic biomass. Energy Procedia 2014; $45: 52-60$.

13. Nassi o Di Nasso N, Roncucci N, Bonari E, Venturi G. Giant reed (Arundo donax L.) as energy crop in central Italy: a review. Ital $\mathbf{J}$ Agron 2013;8:10-7.

14. Shalatov AA, Pereira H. Influence of stem morphology on pulp and paper properties of Arundo donax L. reed. Ind Crop Prod 2002;15:77-83.

15. Ververis C, Georghiou K, Christo Doulakis $\mathrm{N}$, et al. Fiber dimension, lignin and cellulose content of various plant materials and their suitability for paper production. Ind Crop Prod 2004;19:245-54.

16. Coelho D, Marques G, Gutierrez A, et al. Chemical characterization of the lipophilic fraction of giant reed (Arundo donax) fibers used for pulp and paper manufacturing. Ind Crop Prod 2007;26:229-36.

17. Balogh E, Herr JM Jr, Czakó M, Márton L. Defective development of male and female gametophytes in Arundo donax L. (Poaceae). Biomass Bioenerg 2012;45: 265-9.

18. Perdue RE. Arundo donax-source of musical reeds and industrial cellulose. Econ Bot 1958;12:368-404.

19. Pilu R, Bucci A, Badone FC, Landoni M. Giant reed (Arundo donax L.): a weed plant or a promising energy crop? Afr J Biotechnol 2012;11:9163-74.

20. Polunin 0, Huxley A. Flowers of the Mediterranean. London: Hogarth Press; 1987.

21. Bucci A, Cassani E, Landoni $\mathrm{M}$, et al. Analysis of chromosome number and spec- ulations on the origin of Arundo donax L. (giant reed). Cytol Genet 2013;47:237-41.

22. Onofry A. La Canna Comune (Arundo donax L.). Roma: Cremonese Libraio Editore; 1940.

23. Vecchiet M, Jodice R, Schenone G. Agronomic research on giant reed (Arundo donax L.) management system and cultivation of two different provenances. Proceedings of the $9^{\text {th }}$ European Bioenergy Conference, 1996 June 24-27, Copenhagen, Denmark. pp 644-48.

24. Spencer DF, Liow P, Chan W, Ksander GG. Estimating Arundo donax L. shoot biomass. Aquat Bot 2006;84:272-6.

25. Cosentino SL, Copani V, Scalici G, Scandurra $\mathrm{S}$. La produttività del canneto (Arundo donax L.) in relazione alla tecnica di impianto. Proceedings of the XXXIX SIA Congress, 2010 Sept 20-22, Rome, Italy. pp 87-8.

26. Bonfiglio T, Orlandi F, Aguilera F, Fornaciari M. Performance of the species Arundo donax L. for the production of biomass at different cultivation input. Proceedings of the XVII National Congress on Agrometeorology, 2014 Jun 10-12, Rome, Italy. pp 47-8.

27. Bransby DI. U.S. Patent No. 6,389,746. Washington, DC: U.S. Patent and Trademark Office; 2002.

28. Bezzi G, Monti A, Venturi G. [Colture da energia: tecniche di coltivazione e gestione agronomica.] Agricoltura 2006;30:2430. [Article in Italian]

29. Saltonstall K, Lambert A, Meyerson LA. Genetics and reproduction of common (Phragmites australis) and giant reed (Arundo donax). Invas Plant Sci Mana 2010;3:495-505.

30. Cavallaro V, Patanè C, Tringali S, Cosentino SL. Influence of substrate hormonal composition on in vitro multiplication of Arundo donax L. Ital J Agron 2008;3:477-8.

31. Tringali S, Cavallaro V, Patanè $\mathrm{C}$, et al. Influenza dell'epoca di trapianto sull'ambientamento di piantine micro propagate di Arundo donax L. in apprestamenti diversi di protezione. Proceedings of the XXXIX SIA Congress, 2010 Sept 20-22, Rome, Italy. pp 185-6.

32. avallaro $\mathrm{V}$, Patanè $\mathrm{C}$, Cosentino $\mathrm{SL}$, et al. Optimizing in vitro large scale production of giant reed (Arundo donax L.) by liquid medium culture. Biomass Bioenerg 2014;69:21-7.

33. Wijte AHBM, Mizutani T, Motamed ER, et al. Temperature and endogenous factors cause seasonal patterns in rooting by stem fragments of the invasive giant reed Arundo donax (Poaceae). Int J Plant Sci 2005;166:507-17.

34. Gherbin P, De Franchi AS, Lupo F. 
Esperienze sulla propagazione della canna comune (Arundo donax L.). Proceedings of the XXXIX SIA Congress, 2010 Sept 20-22, Rome, Italy. pp 262-3.

35. Copani V, Cosentino S, Scandurra S. Propagation of Arundo donax L. by means of rhizome and stem cuttings. Ital J Agron 2008;3:511-2.

36. Gherbin P, Giampaoli A, Bimbatti M, et al. Esperienze di propagazione della canna comune (Arundo donax L.) per talea di fusto in pieno campo. Proceedings of the XXXIX SIA Congress, 2010 Sept 20-22, Rome, Italy. pp 111-2.

37. Gherbin P, Giampaoli A, Bimbatti M, et al. Esperienze di propagazione della canna comune (Arundo donax L.) per talea di fusto in ambiente protetto. Proceedings of the XXXIX SIA Congress, 2010 Sept 20-22, Rome, Italy. pp 113-4.

38. Copani V, Cosentino SL, Testa G, Scordia D. Agamic propagation of giant reed (Arundo donax L.) in semi-arid
Mediterranean environment. Ital J Agron 2013;8:18-24.

39. Copani V, Cosentino S, D'Agosta G, Mantineo M. Validità di differenti metodi di propagazione per l'impianto di una coltura di canna comune (Arundo donax L.). Proceedings of the XXXV SIA Congress, 2003 Sept 16-18, Portici, NA, Italy. pp 1638.

40. Pari L, Gallucci F, Suardi A, et al. Arundo donax planting prototype. Proceedings of the Technology and management to increase the efficiency in sustainable agricultural systems congress, 2009 Sept 1-4, Rosario, Argentina. pp 1-6.

41. Boland JM. The importance of layering in the rapid spread of Arundo donax (giant reed). Madrono 2006;53:303-12.

42. Monteleone M, Gherbin P, Quaglietta Chiarandà F. Analisi funzionale di crescita di un ibrido di sorgo da cellulosa sottoposto a diversi regimi iriigui: I) approccio metodologico. Rivista di Agronomia
1996;1:44-9.

43. Cosentino SL, Copani V. Canna commune per la destinazione energetica - Il punto sulla propagazione agamica negli ambienti del meridione d'Italia. Sherwood-foreste ed alberi oggi 2012;183:58-65. [Article in Italian]

44. Cosentino SL, Copani V, Mantineo M, et al. Giant reed (Arundo donax L.) propagation by means of stem cuttings. Ital J Agron 2009;4:760-7.

45. Cosentino SL, Copani V, Patanè C, et al. Agronomic, energetic and environmental aspects of biomass energy crops suitable for Italian environments. Ital J Agron 2008;2:81-95.

46. Di Candilo M, Ceotto E. Canna comune nel nord Italia. Influenza delle tecniche di propagazione sulle prestazioni della coltura. Sherwood-foreste ed alberi oggi 2012;183:66-71. [Article in Italian] 